\title{
Work in Progress: Measuring Dispositions Toward Teaching Strategies and Their Reported Use
}

\section{Dr. Eugene Judson, Arizona State University}

Eugene Judson is an Associate Professor of for the Mary Lou Fulton Teachers College at Arizona State University. His past experiences include having been a middle school science teacher, Director of Academic and Instructional Support for the Arizona Department of Education, a research scientist for the Center for Research on Education in Science, Mathematics, Engineering and Technology (CRESMET), and an evaluator for several NSF projects. His first research strand concentrates on the relationship between educational policy and STEM education. His second research strand focuses on studying STEM classroom interactions and subsequent effects on student understanding. He is a co-developer of the Reformed Teaching Observation Protocol (RTOP) and his work has been cited more than 1600 times and his publications have been published in multiple peer-reviewed journals such as Science Education and the Journal of Research in Science Teaching.

Lydia Ross, Arizona State University

Prof. James A. Middleton, Arizona State University

James A. Middleton is Professor of Mechanical and Aerospace Engineering and Director of the Center for Research on Education in Science, Mathematics, Engineering, and Technology at Arizona State University. For the last three years he also held the Elmhurst Energy Chair in STEM education at the University of Birmingham in the UK. Previously, Dr. Middleton was Associate Dean for Research in the Mary Lou Fulton College of Education at Arizona State University, and Director of the Division of Curriculum and Instruction. He received his Ph.D. in Educational Psychology from the University of Wisconsin-Madison in 1992, where he also served in the National Center for Research on Mathematical Sciences Education as a postdoctoral scholar.

\section{Prof. Stephen J. Krause, Arizona State University}

Stephen Krause is professor in the Materials Science Program in the Fulton School of Engineering at Arizona State University. He teaches in the areas of introductory materials engineering, polymers and composites, and capstone design. His research interests include evaluating conceptual knowledge, misconceptions and technologies to promote conceptual change. He has co-developed a Materials Concept Inventory and a Chemistry Concept Inventory for assessing conceptual knowledge and change for introductory materials science and chemistry classes. He is currently conducting research on NSF projects in two areas. One is studying how strategies of engagement and feedback with support from internet tools and resources affect conceptual change and associated impact on students' attitude, achievement, and persistence. The other is on the factors that promote persistence and success in retention of undergraduate students in engineering. He was a coauthor for best paper award in the Journal of Engineering Education in 2013.

\section{Dr. Casey Jane Ankeny, Arizona State University}

Casey J. Ankeny, PhD is lecturer in the School of Biological and Health Systems Engineering at Arizona State University. Casey received her bachelor's degree in Biomedical Engineering from the University of Virginia in 2006 and her doctorate degree in Biomedical Engineering from Georgia Institute of Technology and Emory University in 2012 where she studied the role of shear stress in aortic valve disease. Currently, she is investigating cyber-based student engagement strategies in flipped and traditional biomedical engineering courses. She aspires to understand and improve student attitude, achievement, and persistence in student-centered courses.

\section{Dr. Ying-Chih Chen, Arizona State University}

Ying-Chih Chen is an assistant professor in the Division of Teacher Preparation at Mary Lou Fulton Teachers College at Arizona State University in Tempe, Arizona. 
His research takes two distinct but interrelated paths focused on elementary students' learning in science and engineering as well as in-service science teachers' professional development. The first focus involves how language as a learning tool improves students' conceptual understandings, literacy, and representation competencies in science. His second research focus is on how in-service teachers develop their knowledge for teaching science and engineering in argument-based inquiry classrooms. This research is aimed at developing measures of teachers' Pedagogical Content Knowledge (PCK) for adopting the argumentbased inquiry approach, as well as developing tools to capture the interactive nature of PCK.

\section{Prof. Robert J. Culbertson, Arizona State University}

Robert J. Culbertson is an Associate Professor of Physics. Currently, he teaches introductory mechanics and electrodynamics for physics majors and a course in musical acoustics, which was specifically designed for elementary education majors. He is director of the ASU Physics Teacher Education Coalition (PhysTEC) Project, which strives to produce more and better high school physics teachers. He is also director of Master of Natural Science degree program, a graduate program designed for in-service science teachers. He works on improving persistence of students in STEM majors, especially under-prepared students and students from under-represented groups.

\section{Prof. Keith D. Hjelmstad, Arizona State University}

Keith D. Hjelmstad is Professor of Civil Engineering in the School of Sustainable Engineering and the Built Environment at Arizona State University.

\section{Dr. Yong-Seok Park, Arizona State University}

Yong-Seok Park is currently a postdoctoral associate at Arizona State University in the STEM education research group headed by Dr. Krause. He earned his Master's degree at George Washington University and his Doctorate at the Virginia Polytechnic Institute and State University. His research interests lie in undergraduate STEM education research and engineering design education. 
Measuring Dispositions toward Teaching Strategies and Reported Use 


\section{Background and Purpose}

In this report we describe the development and validity testing of a new assessment instrument that was designed to evaluate the dispositions of engineering faculty members regarding particular classroom strategies. The instrument, named the Value, Expectancy, and Cost of Testing Educational Reforms Survey (VECTERS), was designed to assess attitudes regarding specific student-centered classroom strategies and to collect self-reported use of those classroom strategies. The desire to develop this instrument emanated from the project evaluation of an NSF-funded Improving Undergraduate Science Education (IUSE) project at a large college of engineering in the southwestern United States.

The IUSE project provides professional development for pairs of faculty members from multiple engineering disciplines (e.g., materials science, civil engineering) who, in turn, provide professional development for colleagues in their respective departments. The professional development is designed to promote student-centered pedagogy among undergraduate engineering courses. The theoretical underpinnings of the advocated pedagogy are strongly related to tenets laid out in How Students Learn ${ }^{1}$. In general, the professional development encourages instructors to move their classrooms toward being environments where students have voice, instructors are responsive to varying student backgrounds, and relevancy between coursework and real-world applications are made clear. In sum, these are considered studentcentered pedagogical strategies.

A goal of the IUSE project evaluation is to determine the degree to which instruction is studentcentered before and after professional development. This is accomplished through direct observation using the Reformed Teaching Observation Protocol (RTOP) ${ }^{2}$ (Sawada et al, 2002) and by administering, as a pre- and post-assessment, the Approaches to Teaching Inventory (ATI) ${ }^{3}$ survey instrument.

Though the RTOP and ATI are effective in providing snapshots of instruction and general attitudes about teaching, these instruments do not uncover reasons why instructors may or may not implement strategies. Ongoing interviews with selected participants will help to unearth those rationales. However, interviews can be cumbersome and difficult to support, particularly when funding is limited. To support and possibly supplant some elements of interviews, the IUSE project team has developed the VECTERS. 


\section{VECTERS Framework and Design}

The IUSE professional development promotes concepts of student-centered learning among instructors. But rather than assess beliefs regarding grand ideas such as constructivism and inquiry, it was decided early that VECTERS should focus on the implementation of specific classroom strategies. Three strategies cut across the IUSE professional development:

1. Using formative feedback to adjust instruction

2. Integrating real-world applications

3. Facilitating student-to-student discussion

Although these strategies are not necessarily ground-breaking, they are nonetheless rare in traditional undergraduate engineering courses, especially in archetypal large lecture hall environments. ${ }^{4,5}$ The above three strategies provided the dimensions of VECTERS, but its constructs were based on expectancy theory tenets.

More often expectancy and motivation are described from the student perspective. The expectation of how well a student will perform on a task is viewed as influencing effort and consequently performance. ${ }^{6}$ Related to the expectancy of success is the value that individuals place on attainment of an end goal. The attainment value therefore also predicts effort and determination. ${ }^{7,8}$ Value is sometimes equated as a combination of the value of the input plus the value of the output. This groups the cost of achieving a goal with the attraction of achieving the goal. We chose to separate these elements of value. The input values are considered costs and the price tag of what someone has to give up in order to achieve a task can significantly predict decisions to pursue a goal. ${ }^{9}$

Although studied less often than student perspective alone, some researchers have found connections between teacher motivation and student performance. For example, Lam ${ }^{10}$ found that the intrinsic motivation of secondary teachers to teach (e.g., enjoying using a new teaching approach) was directly related to students' own intrinsic motivation and to students' perception of teacher support. Regarding whether instructors choose to integrate specific strategies, much recent literature is related to decisions to integrate technology into the classroom. Mueller et al ${ }^{11}$ found that the variables contributing most to the likelihood of integrating technology were positive experiences, comfort with the strategy, belief that the strategy was a valuable instructional tool, and personal efficacy. Researchers have also highlighted the conflict of intrinsic motivation with external costs as predictors of implementation. ${ }^{12,13}$ Ertmer referred to external costs such as hardware and external support as first-order barriers, but found that second-order barriers were more often the gatekeepers of implementation. Second order barriers include factors such as belief in success and confidence in the effectiveness of a strategy.

In general, implementation of an educational reform often meets limited success for one or more of three reasons: perception of low value, belief of likely to fail, and assessment of high cost. In many cases the reform is never even transferred from professional development to the classroom because an instructor believes the strategy will have little or no added value for students; or 
because instructors anticipate that instituting the strategy will lead to a less effective learning environment; or simply because instructors consider the expenditure of time and materials too great of a price tag to pay.

It is also noted that the construction of VECTERS was influenced by the work of Abrami, Poulsen, and Chambers. ${ }^{14}$ Their work had the different focus of determining how the obstacles of value, expectancy, and cost affected the implementation of cooperative learning among K-12 classroom teachers. In so doing, they developed the cooperative learning implementation questionnaire (CLIQ). VECTERS was modeled on the CLIQ format of focusing on a specific strategy (or, in this case, three strategies) and providing groups of items based on value, expectancy, and cost.

\section{Value}

The construct of value is tied to benefit. The recipient of benefit is most commonly seen as the students, but the beneficiary can also be the instructor. Implementing a classroom strategy may deemed as having potential benefit for students but it can also be supposed that the strategy can have detrimental effect (i.e., negative value). VECTERS contains eleven value items. Eight of the value items address perceived value (negative and positive) for students; and three of the value items focus on how implementing a classroom strategy may have direct value for the instructor.

\section{Expectancy}

The expectancy construct hinges on the vision of the learning environment when the strategy is implemented. These visions, or expectations, of the learning environment outcome are further categorized by internal and external attribution types. That is, expectation of success, or lack thereof, might be attributed to students' ability to "handle" the strategy, or might be attributed to the instructor's view of their own ability to implement the strategy. Further, expectation of success could be externally attributed to the physical classroom environment - a lecture hall setting versus a small classroom, or hundreds of students versus a couple of dozen students. VECTERS contains ten expectancy items. Five of these items align with expectancy related to students, two items are focused on expectation of success due to the instructor's capacity, and three items associate expectancy of success with the physical environment or the actual content itself.

\section{Cost}

Cost items address the perceived expenditures of implementing a classroom strategy. VECTERS includes five cost items. Among these five items, three address time costs, one item addresses the cost of teaching assistants, and one addresses the cost of overall effort in implementing a strategy. 


\section{Overall Design}

The 26 value, expectancy, and cost items appear on VECTERS as a mix of both negative and positive statement to which respondents indicate their level of agreement on a Likert four-point scale, from strongly agree to strongly disagree. Participants respond to the 26 items for each of the three classroom strategies (formative feedback, real-world applications, and initiating student-to-student discussions), thus yielding 78 datum points.

VECTERS additionally contains questions to collect demographic information about the instructors as well as general information about the engineering course they are reflecting upon when responding to VECTERS. Instructor information includes information such as gender, ethnicity, and years of experience. Course information includes items to indicate the course-level (100 to 400), whether the course is required, and the number of students typically enrolled.

\section{Method}

Although the development of VECTERS began with the purpose of using it only as a local tool, we quickly developed two other goals. The first of these goals was to test the validity of VECTERS and develop and understanding of relationships among items. Assuming VECTERS passed reasonable validity criteria, the second goal was to determine dispositions toward studentcentered teaching strategies from a large pool of engineering faculty across the United States.

The authors' institution is among the 20 largest colleges of engineering in the United States, as acknowledged by ASEE ${ }^{15}$. It was decided to determine the dispositions from faculty members from the other 19 largest colleges of engineering. Smaller colleges of engineering were not included in this test of VECTERS because the authors wished to have responses from similarly sized colleges that could generally be compared to those of faculty members participating in our IUSE professional development.

Engineering faculty members were invited via email to complete VECTERS online. The email invitation was sent to the email addresses of approximately 6300 engineering faculty members. A total of 286 responses were received. While the total amount of responses received was suitable to conduct validity testing and to determine the dispositions of respondents, the response rate was low. Unfortunately, it is not possible to determine the exact response rate because the request was sent to all available email addresses of engineering faculty members listed on college websites and many of those email addresses were associated with faculty who do not teach undergraduate courses. Even with this in mind, it is surmised that response rate was well below 10 percent. This leads to the possibility that those who volunteered to complete VECTERS may be a skewed sample of individuals who are perhaps interested in engineering education.

VECTERS includes a mix of both positive and negative statements. Therefore, data received from the respondents were adjusted so that all values among the 78 items were aligned. That is, data from negatively worded value and expectancy items were adjusted so that a 4 on the 1 to 4 scales indicated perception of high value or high expectancy of success. Likewise, data from cost 
items that implied high expenditure (e.g., implementing this strategy takes too much preparation time) were adjusted so that a response of 4 indicated the respondent viewed cost as being high. Therefore, if a respondent provided high rankings across all three dimensions, this indicated the respondent believed the strategy had strong value, expected success, and viewed the cost of time and/or materials as high.

Internal Consistency. Validity of VECTERS was assessed by calculating Cronbach's alpha coefficients. Cronbach's alpha aids in understanding the interrelatedness among items and points to how well items are measuring the same construct (DeVallis, 2003). The Cronbach's alpha coefficient was first determined across all 26-items for all three strategies (i.e., 78 items collectively). However, VECTERS can be considered as three sub-instruments addressing the strategies of formative feedback, real-world applications, and student-to-student discussion. Therefore, Cronbach's alpha coefficient calculations were applied to each of the three subinstruments. As recommended by DeVallis ${ }^{16}$, Cronbach's alpha levels of 0.7 or higher were desired.

Construct validity. VECTERS construct validity was evaluated by examining relationships between respondents' self-reports of extent to which the three strategies are currently being implemented and are planned to be implemented. For each strategy, a 2x3 matrix was produced; these indicated the relationship between implementation time (current and planned) with VECTERS mean ratings (value, expectancy, cost). The supposition was that those scoring higher on VECTERS' value and expectancy items would be more likely to currently be integrating a classroom strategy and would be more likely to plan on using the strategy in the future (either initiating or continuing to use). Additionally, it was conjectured that individuals who used a strategy more often would be less likely to consider the strategy to have a high cost; therefore a negative relationship between cost and use was expected. While self-reporting of implementation is an imprecise relative measurement, it did provide some means to examine if expected relationships existed.

Construct validity was further examined by applying orthogonal (varimax) rotation factor analysis. Analysis was applied to VECTERS' three sub-tests (formative feedback, real-world applications, and student-to-student discussion).

\section{Results}

The internal consistency for VECTERS items was high (Cronbach's $\alpha=.90$ ). Because VECTERS can be considered as three sub-instruments, comprised of 26 items separately addressing the three classroom strategies, VECTERS was accordingly examined. Cronbach's alpha values for formative feedback, real-world applications, and student-to-student discussion $(0.83,0.76,0.82$, respectively) were all above 0.7 thus implying acceptable reliability for understanding patterns across groups.

Mean responses regarding the extent to which respondents used a particular strategy, now and in the future, were calculated. Faculty members indicated on a Likert scale if they were using or 
planned to use each of the three strategies from "not at all" (value $=1$ ) to "entirely" (value $=4$ ). Results indicated that real-world applications were used most often, with the other two strategies approximately equivalent in use (Table 1).

Table 1. Current and future use of specific classroom strategies.

\begin{tabular}{lcccccc}
\hline & \multicolumn{2}{c}{ Formative Feedback } & \multicolumn{2}{c}{ Real-world Applications } & \multicolumn{2}{c}{ Student-to-student discussion } \\
& Mean & Std. Dev. & Mean & Std. Dev. & Mean & Std. Dev. \\
\cline { 2 - 7 } Current use & 2.45 & .90 & 3.15 & .80 & 2.58 & 1.1 \\
Future use & 2.69 & .91 & 3.31 & .73 & 2.83 & 1.0 \\
\hline
\end{tabular}

Table 2 provides correlations between mean scores for the constructs of value, expectancy and cost, per each classroom strategy, with the reported level of implementation of the strategy both now and planned for the future.

Table 2. Correlations (r-value): Implementation with VECTERS Constructs

\begin{tabular}{|c|c|c|c|c|}
\hline \multirow{3}{*}{$\begin{array}{l}\text { Formative } \\
\text { feedback }\end{array}$} & & Value & Expectancy & Cost \\
\hline & Current use & $.60 * *$ & $.53 * *$ & $-.37 * *$ \\
\hline & Future use & $.62 * *$ & $.50 * *$ & $-.32 * *$ \\
\hline \multirow{2}{*}{$\begin{array}{l}\text { Real world } \\
\text { application }\end{array}$} & Current use & $.44 * *$ & $.34 * *$ & $-.27 * *$ \\
\hline & Future use & $.40 * *$ & $.25 * *$ & $-.13 *$ \\
\hline \multirow{2}{*}{$\begin{array}{l}\text { Student to } \\
\text { student } \\
\text { discussion }\end{array}$} & Current use & $.60 * *$ & $.56 * *$ & $-.45 * *$ \\
\hline & Future use & $.60 * *$ & $.58 * *$ & $-.40 * *$ \\
\hline
\end{tabular}

The relationships found met our predictions. Among all three classroom strategies, instructors' reported use of the strategy was positively correlated to their dispositions regarding the value of the strategy and their expectation of success. The first of these positive relationships implies that instructors who believe a strategy has value for their students and for themselves uses that strategy more often. Similarly, instructors who expect successful implementation of a strategy are more inclined to use that strategy. The relationships, of course, do not indicate causality or directionality. That is, if a causal relationship is in play then belief about value and expectation of success could possibly drive use, but also possible is that using a strategy affects beliefs.

The negative relationships found between cost and reported use also met expectations. These negative relationships imply that higher use correlates to diminished view of the cost of integration. 
Because the constructs of value and expectancy were comprised of items that could be further categorized, we drilled down deeper and conducted an exploratory correlation analysis. Again bivariate analyses were examined between the sub-classifications with reported current implementation and with planned implementation. The subcategories and example items are provided in Table 3 . Because there were only five cost items and these were considered cohesive, no cost subcategories were isolated.

Table 3. Subcategories of Value and Expectancy Items

\begin{tabular}{|l|l|l|l|}
\hline Construct & Sub-category & n & Example item \\
\hline \multirow{3}{*}{ Value } & value for students & 8 & $\begin{array}{l}\text { Using this strategy/tool fosters positive } \\
\text { student attitudes towards learning. }\end{array}$ \\
\cline { 2 - 4 } & value for self & 3 & Using this strategy/tool aids my career. \\
\hline \multirow{4}{*}{$\begin{array}{l}\text { Expectation of } \\
\text { success }\end{array}$} & based on students & 5 & $\begin{array}{l}\text { My students lack the skills necessary to } \\
\text { effectively use this strategy/tool. }\end{array}$ \\
\cline { 2 - 4 } & based on instructor's ability & 2 & $\begin{array}{l}\text { My knowledge of this strategy/tool is } \\
\text { sufficient to implement it successfully. }\end{array}$ \\
\cline { 2 - 4 } & $\begin{array}{l}\text { based on the physical } \\
\text { environment }\end{array}$ & 2 & $\begin{array}{l}\text { The physical set-up of my classroom is } \\
\text { an obstacle to using this strategy/tool. }\end{array}$ \\
\hline
\end{tabular}

It is stressed that this was an exploration of relationships and that confidence in patterns found should be viewed in this light. With that said, only correlations between subcategories and implementation (current use and planned use) that were as strong, or stronger than the correlations found among the complete categories conveyed in Table 2 , are reported here. The greatest predictor for current use $(r=0.6)$ and planned use $(r=0.61)$ of formative feedback was the subcategory of seeing value for students. Similarly, current use $(r=.48)$ and planned use $(r=$ .46) of real-world applications was best predicted by seeing it as valuable for students. This finding was consistent for facilitating student-to-student discussions which was also best predicted by seeing value for students (use now, $r=.61$; planned use, $r=.62$ ).

Nearly all other subcategories were significantly correlated $(\mathrm{p}<.05)$ with both current implementation and planned implementation, with r-values ranging from approximately 0.2 to 0.6. The exception was regarding implementation of student-to-student discussion. For this strategy there was no significant relationship between current use $(r=.01)$ or planned use $(r=$ .05 ) with the belief that using the strategy had value for one's self.

Exploratory factor analysis. Factor analysis was applied to VECTERS' three sub-tests, per the classroom strategies of formative feedback, real-world applications, and student-to-student discussion (26-items per sub-test). Factor analysis was used because we were interested in determining how variables grouped on the basis of strength and correlation, and to assess how well those groupings aligned to the designed constructs of value, expectancy, and cost. Consequently, there was interest in determining if latent variables of common variance could be identified. 
Based on traditional guidelines of retaining all factors with eigenvalues greater than $1^{17}$, initial analysis of eigenvalues and the scree plots suggested retaining five factors for formative feedback, accounting for $59.5 \%$ of the variance; eight factors for real-world applications, accounting for $65.5 \%$ of the variance; and five factors for student-to-student discussion, accounting for $61.6 \%$ of the variance. To streamline comparisons, only six factors were retained for real-world applications because the seventh and eighth factors did not contain at least two items loading at a level of 0.6 or above. The total variance accounted for by the six retained factors for real-world applications was $55 \%$.

The strongest VECTERS items for each of the three sub-tests are provided in Tables 4, 5, and 6. Four items are shown for each factor unless the factor loading was less than 0.6 - in those cases fewer than four items are presented. To streamline presentation, the factors are presented across the three tests as A1, A2, A3 . B1, B2, . C1 . . etc. Items are presented in the third columns in order of descending relative strength. Because some, but not all, expectancy and value items were negatively worded and consequently reverse coded, where appropriate, phrases such as "disagrees that strategy ...," have been included in Tables 4, 5, and 6 to indicate item direction.

Table 4. Formative Feedback, Factor Analysis

\begin{tabular}{|c|c|c|}
\hline Factor & $\begin{array}{l}\text { Cumulative } \\
\text { Variance \% }\end{array}$ & Items Loading Strongest on this Factor \\
\hline A1 & $16.9 \%$ & $\begin{array}{l}\text { Expectancy - disagrees that strategy will not work with my students } \\
\text { Expectancy - disagrees that strategy interferes with actual learning } \\
\text { Value - disagrees that strategy hinders ability to fairly assess students } \\
\text { Expectancy - disagrees that strategy may make class too chaotic }\end{array}$ \\
\hline $\mathrm{A} 2$ & 32.8 & $\begin{array}{l}\text { Value - motivates students } \\
\text { Value - helps students obtain deeper understanding } \\
\text { Value - increases student comprehension } \\
\text { Value - promotes valuable collegiality among students }\end{array}$ \\
\hline A3 & 44.2 & $\begin{array}{l}\text { Cost }- \text { takes too much prep time } \\
\text { Cost }- \text { requires a lot of effort } \\
\text { Cost }- \text { difficult to implement without specialized materials } \\
\text { Cost }- \text { requires considerable use of TAs } \\
\end{array}$ \\
\hline A4 & 52.0 & $\begin{array}{l}\text { Expectancy - I understand this strategy well enough to implement successfully } \\
\text { Expectancy - My knowledge of this strategy is sufficient to successfully implement }\end{array}$ \\
\hline A5 & 59.5 & $\begin{array}{l}\text { Value }- \text { using this strategy aids my career } \\
\text { Value }- \text { is aligned with goals of my college and university }\end{array}$ \\
\hline
\end{tabular}


Table 5. Real-world Applications, Factor Analysis

\begin{tabular}{|c|c|l|}
\hline Factor & $\begin{array}{c}\text { Cumulative } \\
\text { Variance \% }\end{array}$ & Items Loading Strongest on this Factor \\
\hline B1 & $15.4 \%$ & $\begin{array}{l}\text { Value - the strategy is a valuable instructional approach } \\
\text { Expectancy - disagree that strategy interferes with actual learning } \\
\text { Expectancy - disagrees that strategy will not work with my students } \\
\text { Value - disagrees that strategy hinders learning of bright students }\end{array}$ \\
\hline B2 & 25.9 & $\begin{array}{l}\text { Cost - takes too much prep time } \\
\text { Cost - requires a lot of effort } \\
\text { Cost - difficult to implement without specialized materials } \\
\text { Cost - requires considerable use of TAs }\end{array}$ \\
\hline B3 & 34.1 & $\begin{array}{l}\text { Value - increases student comprehension } \\
\text { Value - motivates students }\end{array}$ \\
\hline B4 & 41.7 & $\begin{array}{l}\text { Expectancy - My knowledge of this strategy is sufficient to successfully implement } \\
\text { Expectancy - I understand this strategy well enough to implement successfully }\end{array}$ \\
\hline B5 & 48.6 & $\begin{array}{l}\text { Value }- \text { using this strategy aids my career } \\
\text { Value - is aligned with goals of my college and university }\end{array}$ \\
\hline B6 & 55.0 & $\begin{array}{l}\text { Expectancy - disagrees that physical set-up of my classroom is an obstacle } \\
\text { Expectancy - disagrees that there are too many students to implement successfully }\end{array}$ \\
\hline
\end{tabular}

Table 6. Student-to-Student Discussions, Factor Analysis

\begin{tabular}{|c|c|c|}
\hline Factor & $\begin{array}{l}\text { Cumulative } \\
\text { Variance } \%\end{array}$ & Items Loading Strongest on this Factor \\
\hline $\mathrm{C} 1$ & $19.4 \%$ & $\begin{array}{l}\text { Value - motivates students } \\
\text { Value }- \text { increases student comprehension } \\
\text { Value - fosters positive attitudes towards learning } \\
\text { Value - promotes valuable collegiality among students }\end{array}$ \\
\hline $\mathrm{C} 2$ & 35.2 & $\begin{array}{l}\text { Expectancy - will not work with my students } \\
\text { Expectancy - disagrees that strategy interferes with actual learning } \\
\text { Expectancy - disagrees that strategy inappropriate for the subject taught } \\
\text { Expectancy - disagrees that students lack necessary skills to be effective }\end{array}$ \\
\hline $\mathrm{C} 3$ & 47.4 & $\begin{array}{l}\text { Cost }- \text { takes too much prep time } \\
\text { Cost }- \text { difficult to implement without specialized materials } \\
\text { Cost }- \text { requires considerable use of TAs } \\
\text { Cost }- \text { requires a lot of effort }\end{array}$ \\
\hline $\mathrm{C} 4$ & 55.2 & $\begin{array}{l}\text { Expectancy - My knowledge of this strategy is sufficient to successfully implement } \\
\text { Expectancy - I understand this strategy well enough to implement successfully }\end{array}$ \\
\hline $\mathrm{C} 5$ & 61.6 & $\begin{array}{l}\text { Expectancy - disagrees that physical set-up of my classroom is an obstacle } \\
\text { Expectancy - disagrees that there are too many students to implement successfully }\end{array}$ \\
\hline
\end{tabular}

A crosswalk examination of the factor analyses presented in Tables 4, 5, and 6, led to connections and themes becoming evident. A dimension we termed "functionality" is represented in factors A1, B1, and C2. These three factors share many items that point toward a belief that the strategy simply will work with students and a dismissal of the notion that the strategy somehow interferes with learning. 
Also cutting across all three strategies is a dimension we simply refer to as "expense." The expense dimension (represented by factors A3, B2, and C3) is present among all three of the strategies and the exact same four cost items rank highest across all three strategies. The only cost item that did not load heavily in the expense dimension was the statement that "there is too little time available during class to implement this strategy effectively." This statement about class time had a loading factor of approximately 0.4 for all strategies; however, the other four items had consistent loading factors of about 0.7 to 0.8 . The implication here is that the commodity of class time is viewed differently than the cost of out-of-class expenditures such as TAs, materials, and preparation time.

A third important dimension across all three strategies is termed "student benefit." This is represented by factors A2, B3, and C1. This dimension corresponds to the sentiment that use of a strategy will aid student comprehension and motivate students. The variance explained by the student benefit dimension ranges considerably from $8.2 \%$ for real-world applications to $19.4 \%$ for student-to-student discussion. Why there is this relative breadth and difference in positioning of the student benefit dimension is uncertain. It may be only due to relative strengths of other dimensions or that the use of formative feedback and student-to-student discussion are seen as having more immediate benefit than integration of real-world applications. It is also noted that instructors reported considerably greater use of real-world applications into their classrooms (Table 1) than the other two strategies. The more common use of real-world applications may possibly be diluting and demoting the relative view of its benefit for students.

A dimension of "personal ability" also cut across all three strategies and is represented by factors A4, B4, and C4. As might be anticipated, the two items that addressed personal understanding of how to successfully integrate a strategy were in lockstep. Finally, other dimensions that cut across at least two of the strategies but accounting for comparatively less of the variance than those listed above are the following. Factors A5 and B5 represent a dimension of "job expectation." Additionally, factors B6 and C5 represent a dimension of "physical environment."

\section{Conclusion}

The results of validity testing indicate that VECTERS has legitimacy as an instrument, and essentially as three sub-instruments. Item analysis pointed toward cohesiveness and strong interconnections where it was expected. The examination of construct validity played out well for value and expectancy, as did the relationship between implementation and perception of cost. The relationship indicates that using a strategy is negatively related to perception of high cost. This finding aligns to research indicating that when people perceive a reform to have first-order barriers (i.e., external cost) they are less likely to implement; however users of a reform tend to minimize first-order barriers and focus on the more important second-order barriers such as views about effectiveness and potential for success.

VECTERS is seen has having two useful future roles. First, it can be used as a diagnostic for faculty members. This needn't be limited to engineering faculty since the three classroom strategies (formative feedback, real-world applications, and student-to-student discussion) are 
advocated across multiple disciplines. Using VECTERS as one means of evaluating the dispositions of faculties over time can help to pinpoint mindsets and experiences that are hampering implementation of strategies.

A second useful role for VECTERS may be as a tool that helps to facilitate discussion about teaching. In our IUSE professional development, items will be selected from VECTERS as seeds of conversation among faculty members. Discourse about not only the strategy but the specifics of value, expectation, and cost, are anticipated to enrich dialogue. This type of deeper discussion will hopefully aid instructors in developing introspection regarding their own beliefs and perceived obstacles of implementation.

\section{Acknowledgment}

The authors gratefully acknowledge support of this work by the National Science Foundation under Grant No. 1524527

\section{References}

1. Branford, J. D., \& Donovan, S. M. (2005). How students learn: history, mathematics, and science in the classroom. National AcademiesPress, Washington.

2. Sawada, D., Piburn, M. D., Judson, E., Turley, J., Falconer, K., Benford, R., \& Bloom, I. (2002). Measuring reform practices in science and mathematics classrooms: The reformed teaching observation protocol. School Science and Mathematics, 102(6), 245-253.

3. Trigwell, K., \& Prosser, M. (2004). Development and use of the approaches to teaching inventory. Educational Psychology Review, 16(4), 409-424.

4. Beichner, R. J., Saul, J. M., Abbott, D. S., Morse, J. J., Deardorff, D., Allain, R. J., ... \& Risley, J. S. (2007). The student-centered activities for large enrollment undergraduate programs (SCALE-UP) project. Research-based reform of university physics, 1(1), 2-39.

5. Felder, R. M., \& Brent, R. (1996). Navigating the bumpy road to student-centered instruction. College teaching, 44(2), 43-47.

6. Kirn, A., \& Benson, L. (2015). Engineering students' perceptions of the future: Exploratory instrument development. Paper presented at the $122^{\text {nd }}$ ASEE Annual Conference \& Exposition. Seattle, WA.

7. Shah, J., \& Higgins, E. T. (1997). Expectancyx value effects: Regulatory focus as determinant of magnitude and direction. Journal of personality and social psychology, 73(3), 447.

8. Shu, T. M., \& Lam, S. F. (2011). Are success and failure experiences equally motivational? An investigation of regulatory focus and feedback. Learning and Individual Differences, 21(6), 724-727.

9. Wigfield, A., Tonks, S., \& Eccles, J. S. (2004). Expectancy-value theory in cross-cultural perspective. In D. M. McInerney \& S. Van Etten (Eds.), Research on sociocultural influences on motivation and learning, Vol. 4: Big theories revisited (pp. 165-198). Greenwich, CT: Information Age Publishing. 
10. Lam, S. F., Cheng, R. W. Y., \& Ma, W. Y. (2009). Teacher and student intrinsic motivation in projectbased learning. Instructional Science, 37(6), 565-578.

11. Mueller, J., Wood, E., Willoughby, T., Ross, C., \& Specht, J. (2008). Identifying discriminating variables between teachers who fully integrate computers and teachers with limited integration. Computers \& Education,51(4), 1523-1537.

12. Ertmer, P. A. (1999). Addressing first-and second-order barriers to change: Strategies for technology integration. Educational Technology Research and Development, 47(4), 47-61.

13. Ertmer, P. A., Ottenbreit-Leftwich, A. T., Sadik, O., Sendurur, E., \& Sendurur, P. (2012). Teacher beliefs and technology integration practices: A critical relationship. Computers \& Education, 59(2), 423-435.

14. Abrami, P. C., Poulsen, C., \& Chambers, B. (2004). Teacher motivation to implement an educational innovation: Factors differentiating users and non-users of cooperative learning. Educational Psychology, 24(2), 201-216.

15. Yoder, B. (2014). Engineering by the numbers. ASEE (American Society of Engineering Educators). Retrieved from https://www.asee.org/papers-and-publications/publications/14_11-47.pdf

16. DeVellis, R.F. (2003). Scale development: Theory and applications (2nd ed.), California: Sage.

17. Kaiser, H. F. (1960). The application of electronic computers to factor analysis. Educational and Psychological Measurement, 20(1), 141-151. doi: 10.1177/001316446002000116 